Pragmatics 7:2.147-162.

International Pragmatics Association

DOI: 10.1075/prag.7.2.02god

\title{
THE SEMANTICS OF COMING AND GOING
}

\author{
Cliff Goddard
}

\section{Introduction}

It is often assumed that the English motion verbs come and go can be glossed as motion towards-the-speaker and 'motion not-towards-the-speaker', respectively. This paper proposes alternative semantic analyses which are more complex, but also, it is argued, more descriptively adequate and more explanatory. The semantic framework is the Natural Semantic Metalanguage (NSM) approach developed by Anna Wierzbicka, in which meanings are stated as explanatory paraphrases (explications) couched in a small, standardised and translatable metalanguage based on natural language. A single explication is advanced for come, and it is shown that this unitary meaning is compatible with the broad range of 'appropriateness conditions' on its use (cf. Fillmore 1966, 1975, 1983). The same applies to go. A novel feature of the proposed analysis for come is that it does not rely on the conventional notion that 'deictic projection' is a pragmatic phenomenon. Instead the potential for 'deictic projection' is analysed as flowing directly from the lexical semantics of come. This approach, it is argued, enables an improved account of semantic differences between near equivalents for come and go in various languages.

The paper is structured as follows. §1 gives general background on the NSM theory. $\S 2$ reviews some problems with the semantics of motion, and gives orientation on how they are approached within the NSM framework. $\S 3$ and $\S 4$ address the semantics of English $g o$ and come, respectively. Concluding remarks form $\S 5$.

\section{The NSM approach}

The basic assumptions of the NSM approach (Wierzbicka 1972, 1980, 1988, 1991, 1992, 1996; cf. also Goddard in press) can be stated as follows. (a) Semantic analysis must be conducted in natural language, because technical neologisms, logical formalisms, etc., are not clear until and unless they are explained in ordinary language. (b) Any complex meaning can be decomposed without circularity and without residue into a combination of discrete other meanings. From these assumptions it follows that there must exist in every language a finite set of indefinable terms (semantic primes), the terms one would be left with after an exhaustive reductive paraphrase analysis of the entire lexicon. In addition,

\footnotetext{
${ }^{1}$ I am grateful to Tony Backhouse, David Nash, Jane Simpson, Anna Wierzbicka, and an anonymous referee, for comments on an earlier version of this paper. They are not to be held responsible for errors which remain.
} 
there is a third assumption, (c) the universality hypothesis, according to which the semantic primes of different languages can be matched up in one-to-one correspondence. According to the NSM theory, the irreducible semantic core of any language is a kind of universal mini-language (the 'natural semantic metalanguage').

In some respects Wierzbicka's premises resemble those of Ray Jackendoff (1983, 1990), who also believes in a set of conceptual primitives which manifests itself in both lexical and grammatical domains, except for the fact that in Jackendoff's view the primitives are 'abstract' and not to be identified with ordinary word-meanings. Another point of divergence is that Wierzbicka believes that semantic analysis can (and should) be exhaustive, whereas Jackendoff allows for a residue of unstatable meaning to remain even after analysis into conceptual primitives has gone as far as it can go.

After a great deal of trial-and-error experimentation in diverse areas of semantic analysis, and taking into account a number of careful cross-linguistic studies (Goddard and Wierzbicka Eds, 1994), NSM researchers believe they have identified nearly sixty semantic primes, though it is not claimed that this inventory is final or complete. ${ }^{2}$ The current primes include, among others, the meanings indicated by the primary senses of English words like: I, YOU, SOMEONE, SOMETHING, THIS, DO, HAPPEN, MOVE, KNOW, THINK, WANT, SAY, WHERE/PLACE, WHEN/TIME, BECAUSE, NOT, MAYBE, GOOD, BAD, LIKE, KIND OF, PART OF. These elements are held to designate meanings which are impervious to (non-circular) definition and universal in the sense of having equivalents in all languages. That is, the claim is that the meanings just listed could equally well be presented as a list of items in Yankunytjatjara, Malay, Japanese, Russian, Ewe, or any other language. The current inventory of semantic primes is displayed in full in Table One (Wierzbicka 1996).

Some points of clarification should be mentioned, however. First, the equivalents of semantic primes are not always separate words, but may be affixes or fixed phrases (phrasemes); nor are they are necessarily morphologically simple. Second, common everyday terms are prone to polysemy and exponents of semantic primes are not exceptions in this regard. Exponents of the same prime may be polysemous in different ways in different languages. This can confuse the picture until the polysemy is sorted out and justified on language-internal grounds (for detailed studies see Goddard 1991; Harkins 1995). Thirdly, a semantic prime may be expressed by variant forms in different combinatorial or positional contexts, a phenomenon known within NSM theory as 'allolexy'. For example, the English word thing can be regarded as an allolex of SOMETHING when combined with determiners and quantifiers: e.g. THIS SOMETHING $=$ this thing, THE SAME SOMETHING = the same thing. As an example of another kind, English me can be seen as post-verbal allolex of the primitive I. For discussion of techniques for identifying exponents of semantic primes, see Goddard (1991), Goddard and Wierzbicka (Eds, 1994, esp. Ch. 2 and 17).

\footnotetext{
${ }^{2}$ In recent years the inventory of semantic primes has been expanding. Of the 55 primes put forward in Wierzbicka (1996), no fewer than 16 are 'new' in the sense that they were not included in the set of crosslinguistic studies published as Semantic and Lexical Universals (Goddard and Wierzbicka Eds, 1994). Though a certain amount of cross-linguistic research has been carried out on these new entrants, their claim to universal status is not as secure as that of the SLU set. Furthermore, there are some additional elements under current consideration, including TRUE, BODY, DIE, HAVE (alienable possession), TOUCH and/or ON (contact). This expanded set is being tested in a set of unrelated languages in work underway for publication in Goddard and Wierzbicka Eds. (forthcoming).
} 
Table One: Proposed semantic primes (after Wierzbicka 1996)

Substantives:

Determiners:

Quantifiers:

Mental predicates:

Speech:

Actions, events, movement:

Existence and life:

Evaluators and descriptors:

Time:

Space:

Logical concepts:

Intensifier, augmentor:

Taxonomy, partonomy:

Similarity:
I, YOU, SOMEONE, PEOPLE/PERSON; SOMETHING/THING

THIS, THE SAME, OTHER/ELSE

ONE, TWO, ALL, MANY/MUCH, SOME

WANT, FEEL, THINK, KNOW, SEE, HEAR

SAY, WORD

DO, HAPPEN, MOVE

THERE IS, LIVE

GOOD, BAD, BIG, SMALL

WHEN/TIME, NOW, AFTER, BEFORE, A LONG TIME, A SHORT

TIME, FOR SOME TIME

WHERE/PLACE, HERE, UNDER, ABOVE; FAR, NEAR; SIDE; INSIDE

NOT , MAYBE, IF, CAN, BECAUSE, IF ... WOULD

VERY, MORE

KIND OF, PART OF

LIKE

The NSM metalanguage of course includes not only a lexicon, but also a syntax. It is claimed that there are certain combinatorial patterns among the lexical primes which can be found in all languages. To give some simple examples relevant to the present paper, it is claimed that in all languages one can form expressions equivalent in meaning to the expressions listed in (a)-(c) below. Note that how such expressions are constructed from a formal point of view is irrelevant providing that the same overall meaning is conveyed. For example, in some languages a 'clausal complement' of WANT is expressed by what looks like an independent clause, roughly: I-want-it, I-do something, but if such a structure expresses the same meaning as I WANT TO DO SOMETHING, it qualifies as an equivalent for semantic purposes. It is not possible here, nor is it really necessary, to describe the syntax of the NSM metalanguage in any detail (cf. Wierzbicka 1996: Ch. 3; Goddard Ed. 1997; Goddard and Wierzbicka Eds. forthcoming).

a. this person, in this place, at this time

in another place (somewhere else), in the same place

before this, after this

b. $\quad \mathrm{X}$ wants to do something

$\mathrm{X}$ moved for some time

c. if $\mathrm{X}$ happens, after this $\mathrm{Y}$ will happen

In the NSM system, the meaning of a semantically complex expression (be it a word or a grammatical construction) is described by means of an explanatory paraphrase (an explication) framed entirely within the semantic metalanguage as just outlined. An accurate explication should be substitutable without change of meaning in place of the expression which is being described. Ideally, this means that native speakers agree that the explication and the original expression mean the same thing. It also means that the explication will 
correctly predict the range the use of the original expression, and that the same set of entailments will follow from the explication as from the original. Notice that the NSM approach to meaning is what philosophers know as a purely 'intensional' conception of meaning. In particular, there is no dichotomy drawn between 'denotational' and 'expressive' meaning, as in classical truth-conditional semantics and more recent developments in formal semantics.

\section{The semantics of motion}

The most fundamental challenges to a semantic account of motion are, firstly, to decide whether the concept of motion is definable or indefinable, and, secondly, to articulate the relationships between motion, time, and location in space. We can see contrary positions on these issues in the works of John Locke and G. W. Leibniz in the seventeenth century. In his Essay Concerning Human Understanding, Locke (1976: 84) recognised the dependence of the concept of motion on that of space, but still maintained that they were 'very distinct ideas ... Motion can neither be nor be conceived without space, and yet motion is not space nor space motion'. In a famous passage (Locke 1976: 221-2), he used motion as an example of a 'simple idea' (i.e. an indefinable), ridiculing those who try to define it as passage from one place to another: 'What do they do more than put one synonymous word for another? For what is passage other than motion? And if they were asked what passage was, how would they better define it than by motion?'

In his critique of Locke, Leibniz (1981: 297) took the opposite view, insisting that the concept of motion is definable, and that 'the definition which says it is change of place deserves respect'. Actually, Locke himself sometimes seems to slip into this view himself, as for instance, when he designates 'distance' as a 'mode of space' and then speaks of 'motion being nothing but the change of distance between any two things' (1976: 81, 85). Of course, to analyse motion as 'change of place' (or as change of distance) means assuming that 'change' is a semantically simpler concept than motion itself. As a matter of fact, Leibniz did believe that 'change' was a simple and indefinable concept, but this is by no means an obvious proposition. On purely intuitive grounds, words like go and move would probably strike most people as simpler than change, and children no doubt start using the words like go and move well before they use change. In any case, even if motion is reduced to 'change of place', it still remains to spell out the relationship between change and time.

In modern times, Ronald Langacker (1987: 166-8) upholds the Leibnizian position on motion: 'Spatial motion is change through time in the location of some entity'. If the formula $\left[\mathrm{m} / \mathrm{l}_{i}\right] / t_{i}$ indicates an entity $m$ at the location $l_{i}$ at moment $t_{i}$ in conceived time, then the conceptualisation of spatial motion, according to Langacker, involves the movement of $m$ along path $\left[l_{0}>l_{1}>l_{2}>\ldots\right]$ during the time-span $\left[t_{0}>t_{1}>t_{2}>\ldots\right]$, such that $\left[\mathrm{m} / \mathrm{l}_{0}\right] t_{0}>\left[\mathrm{m} / \mathrm{l}_{1}\right] t_{1}>\left[\mathrm{m} / \mathrm{l}_{2}\right] t_{2}>\ldots$, and where $l_{i}$ and $l_{i+1}$ are contiguous and $t_{i}$ and $t_{i+1}$ are successive, in some appropriate sense.

One difficulty with this line of analysis is brought to light by the ancient "paradox of the flying arrow' attributed to Zeno of Elea. If the flying arrow is in a different location at every moment of its flight, this seems to imply that it is at rest at every moment of its flight, and if it is always at rest, when does it move? Over the centuries many solutions 
have been proposed to this brain-teaser, most recently drawing on sophisticated mathematical concepts about infinite series and infinite sets (cf. Russell 1917: 80-90). From a semantic point of view, however, one feels that since the paradox is framed in terms of ordinary language concepts it ought to be possible to escape it without recourse to mathematics. In this respect, Aristotle's answer to Zeno may have something to offer (cf. Sorabji 1988: 332-3). He said that time (i.e. duration) is not truly composed of 'nows' (that is, of moments), and that what may be true at a moment is not necessarily true over a period. It is not surprising that moments are not attended by motion, says Aristotle, because duration is one of the necessary attributes of motion.

Oddly enough, the temporal aspects of motion tend not to be highlighted in most contemporary linguistics. To see this, we can consider the influential account of a 'basic motion event' by Leonard Talmy (1985: 60-1). Talmy identifies four components: (a) an object, which he calls the 'figure' but which many others refer to as the 'theme' (b) moving (c) along a 'path' (d) with respect to another reference-object, which Talmy calls the 'ground'. The 'source' (origin point) and 'goal' (destination) can be considered sub-types of path. Talmy can be seen as belonging in Locke's camp, in that he seems to regard motion as a semantic fundamental. He proposes the notation MOVE to designate the basic predicate of motion, in opposition to $\mathrm{BE}_{\mathrm{L}}$ 'be located'. Talmy's treatment plays down the temporal dimensions of motion, except insofar as a time-span is implied by the existence of the 'path'.

It is notable that both Langacker's and Talmy's schemas are tailored to movement from one place to another (sometimes called 'translational motion') and make no attempt to draw out the links with other kinds of movement (e.g. turning around or moving one's hand).

Many of Talmy's ideas are incorporated in the treatment of motion adopted by Ray Jackendoff $(1983,1990)$ within his theory of conceptual semantics. Jackendoff adopts GO and $\mathrm{BE}$ as basic 'conceptual functions', corresponding to Talmy's MOVE and $\mathrm{BE}_{\mathrm{L}}$, and assigns them the argument structures shown in (a) and (b) below ${ }^{3}$. Notice that 'source' and 'goal' are included as intrinsic to the GO-event, and that the overall character of the depiction is distinctly static.

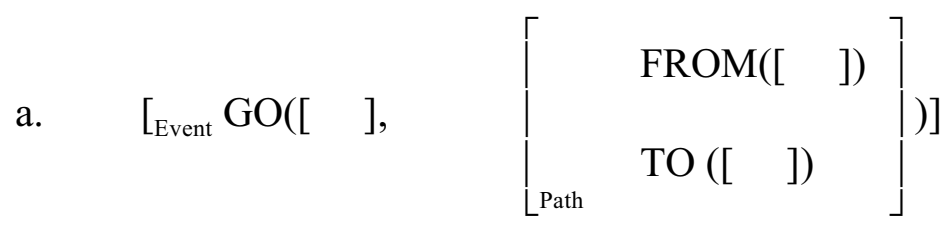

b. $\quad[$ State $B E([\quad],[$ Place $])]$

To account for the fact that a go-sentence, such as The bird went from the ground

3 Actually, in more recent, as yet unpublished, work (referred to in Jackendoff 1996: 108), Jackendoff had decomposed the function GO along Leibnizian lines. 
to the tree, implies a be-sentence, such as The bird is in the tree, as its 'end-state', Jackendoff postulates the following 'rule of inference':

At the termination of $\left.\left.{ }_{\text {Event }} \mathrm{GO}\left([\mathrm{X}],{ }_{\text {Path }} \mathrm{TO}([\mathrm{Y}])\right]\right)\right]$, it is the case that $\left[_{\text {state }} \mathrm{BE}([\mathrm{X}]\right.$, [place $\left.\left.\mathrm{AT}([\mathrm{Y}])]\right)\right]$.

This manoeuvre highlights the difficulties of explaining the interconnectedness between motion and location, if source (FROM) and goal (TO) are taken as unanalysable extensions of GO. The rule of inference appears completely unmotivated. It simply begs the question: Why should $\mathrm{X}$ wind up being at $\mathrm{Y}$ after $\mathrm{X}$ has gone to $\mathrm{Y}$ ?

As for verbs like wiggle, dance, spin, and wave which 'describe the manner of motion of an object but do not imply traversal of a Path', Jackendoff's (1990: 88-9) analysis presents them as essentially unrelated to verbs of translational motion. All verbs which depict merely 'the internal motion of the subject, with no implications with respect to their location, change of location or configuration with respect to any other object' are assigned the following analysis. Notice that MOVE (in the sense of 'internal motion') is regarded as a distinct conceptual primitive to GO.

$$
\text { [Event } \operatorname{MOVE}([\text { Thing }])]
$$

Jackendoff dismisses the challenge of describing the semantic differences between wiggle, dance, spin, and wave on the grounds that they each express 'a different idiosyncratic manner of motion, of a sort not easily decomposable into features. It is hard to imagine features, for example, that might distinguish wiggling from other possible motions, say wriggling' (Jackendoff 1990: 88). Such 'visual distinctions of manner' are relegated to a non-conceptual, quasi-geometrical module of the mind, with the comment that they are 'not the business of conceptual structure at all'. Personally, I find this position disingenuous but it is not a matter we can pursue here; see Stanwood (1993) for an analysis of wave and wiggle.

Coming now to the NSM approach to motion, one can say that, overall, NSM analyses are more elaborate than those of most other current approaches, but that the pay-off is a far better articulation of the relationships between motion, space, and time. To begin with, Wierzbicka (1996) and colleagues have lately adopted the Lockean position that motion cannot be conceptually decomposed, and have postulated the existence of a universal semantic primitive MOVE. Significantly, however, the NSM MOVE is supposed to be neutral between 'translational motion' and 'internal motion', and to provide the conceptual anchor-point for both. Certainly, in contexts like Don't move and I couldn't move, the word MOVE seems to cover both varieties of movement. The primitive move is seen as having a special affiliation with the durational primitive FOR SOME TIME.

To analyse translational motion, additional (independently necessary) semantic primes are drawn upon. As Fillmore (1983: 217) once remarked, 'linear motion or locomotion' is distinguished from other types of motion such as spinning or vibrating precisely by the fact that 'the thing started out at one place at one time and ended up at another place at a later time'. Thus, it is easy to see that the locational primitive BE SOMEWHERE (or BE IN A PLACE), the element THIS, and the concepts of BEFORE and AFTER are implicated in the analysis of source and goal. Essentially, a motional 'source' refers to 
the place where something was before it moved and motional 'goal' to another place, where it is after the movement is over.

1. $\mathrm{X}$ moved from $\mathrm{A}$ to $\mathrm{B}=$

before this, $\mathrm{X}$ was somewhere (in place-A)

after this, $\mathrm{X}$ moved for some time

because of this, after this $\mathrm{X}$ was somewhere else (in place-B)

It would be easy to misinterpret explication (1) as an attempt to define 'translational motion' in terms of stationary 'internal motion'; so it is important to recall that the primitive MOVE is claimed to be vague as to what kind of motion is involved. That is, MOVE does not represent 'internal motion', but a meaning which is neutral in respect of the distinction between 'internal motion' and 'translational motion'. Thus, though explication (1) constitutes a frame in which MOVE can only be understood as depicting translational motion, it does not really amount to an attempt to reduce moving from $A$ to $B$ to 'internal motion' plus change of location. An analogy may help clarify this point, admittedly a rather subtle one. A word like neighbour is vague as to gender, but when it appears in a context like My neighbour is hanging out her washing we realise that a female neighbour must be intended. Similarly, MOVE is vague, but when we see it in a context like ' $\mathrm{X}$ moved for some time; because of this, after this X was somewhere else' we realise that in this context MOVE must be intended to depict translational motion.

Notice that the analyses for 'motional source' and 'motional goal' implicit in (1) are compatible with well-known facts about the extension of source and goal adpositions to other, non-motional grammatical functions. For example, the fact that motional from and to imply the temporal relators BEFORE and AFTER, respectively, helps explain their use in domains such as transformation and transfer of possession, which depend on a 'before-after' schema (cf. Langacker 1987: 166-176).

To explicate directional (i.e. path-like) expressions such as towards and away from, it is necessary to draw on the spatial elements NEAR and FAR, and the conditional IF. Consider the following:

2. $\mathrm{X}$ moved towards $\mathrm{A}=$

$\mathrm{X}$ moved for some time

if it moved in the same way for some time, after this it would be near A

Notice that this explication links towards with the concept of nearness, rather than with that of arrival (i.e. being at A). This allows for the fact that I can say that something moved towards A without implying that I think it would have necessarily passed through A's exact location. Of course, the term NEAR is inherently vague - just what distance qualifies as NEAR is a rather subjective matter - but this is as it should be, since the same kind of vagueness characterises towards also. Notice that the explication predicts that it wouldn't make sense to speak of X moving towards A if X were already unambiguously near A. Again this seems the correct result. There is nothing odd about saying Sally sat down some distance from Harry, then she started moving towards him, but it does sound odd to say that 'She sat down near Harry, then started moving towards him (though then she started moving closer to him is quite $\mathrm{OK}$ ). 
The comparable explication for away from is:

3. $\mathrm{X}$ moved away from $\mathrm{A}=$

$\mathrm{X}$ moved for some time

if it moved in the same way for some time, after this it would be far from A

Other path-expressions will call for other spatial elements: up(wards) and down(wards) involve ABOVE and BELOW, into involves INSIDE, and across involves the laterality primitive ON THE SIDE. Many expressions to do with 'manner of motion', notably speed words like quickly and slowly, rely on the time-period primitives A SHORT TIME and A LONG TIME, as well as other elements. It is not necessary for us to go into these details here. Instead, we turn to the main business of the present study, the semantics of English go and come.

\section{The meaning of English go}

Although in various linguistic works, one sees an abstract predicate GO applied to all sorts of things - people, inanimate objects and natural forces alike — ordinary English go is not like that. It sounds perfectly normal to speak of people and animals going from one place to another, but there is something curious and faintly child-like about using go of an inanimate object.

4a. The boys are going down to the river.

4b. The horses are going down to the river.

4c. ?The clouds are going across the sky.

4d. $\quad *$ The rock is going down the hill.

Go is an extremely polysemous word, however, and for this effect to emerge clearly we must confine ourselves to its motional sense. In particular, we must exclude the use of the participial adjective gone as in It's gone. This can apply to anything, living or non-living (e.g. The rock was gone, The clouds were gone), with any implication that the thing moved itself, so to speak. With this caveat in mind, however, we can say that, by and large, motional go in ordinary English is confined to wilful motion by animate beings, and the same applies to come. I will assume, without further justification, that such uses are the central or prototypical uses of go and come. Notwithstanding the existence of certain non-prototypical cases ${ }^{4}$, this paper will focus exclusively on the prototypical meanings.

Two further important properties of go are as follows. On the one hand, it can

\footnotetext{
${ }^{4}$ At least three different categories of non-prototypical motional uses can be identified: (i) about vehicles (When does the bus come?, The plane was going to Sydney), (ii) about natural phenomena (The floodwaters came right up to the front fence. The sun went down/came up) (iii) about inanimate objects in certain conditions (The ball went out of the court, The ball came down at her feet). Instances of type (i) are consistent with a kind of imputed intentionality, because it is part of our understanding of buses, trains, and planes that people are in control of them. Instances of type (ii) are presumably connected with the fact that the meanings of words like sun, tide, and rain refer to the fact that these things move by themselves. Instances of type (iii) often concern objects which have been directed by intentional human action.
} 
combine directly with an indefinite or interrogative location word indicating a goal (as in She went somewhere, or Where are you going?) without the need for any prepositional to-phrase. This seems to imply that the idea of being somewhere is very closely tied in with the meaning of go. On the other hand, go seems more focused on leaving or 'moving on' than on the possibility of arriving anywhere. For example, one can say She went yesterday without implying that she has arrived anywhere, and it is quite possible to think of someone just going along without having to think of any particular destination that the person may have in mind. To a large extent, this paradox can be resolved by the following explication.

5. $\mathrm{X}$ went $=$

before this, $\mathrm{X}$ was somewhere

$\mathrm{X}$ wanted to be somewhere else

because of this, $\mathrm{X}$ moved for some time

because of this, after this $\mathrm{X}$ wasn't in this place any more

$\mathrm{X}$ was somewhere else

To see that the final pair of components is necessary, consider the situation of a frustrated prisoner pacing around in a cell. Even if this person is moving for some time because of wanting to be somewhere else, it doesn't qualify as going. It should also be pointed out that the explication doesn't imply that the place which the mover wound up in was necessarily the intended destination (or even that the mover had any particular destination in mind).

Interestingly, the situation changes a bit when a to-phrase is added. Saying She went to the shops implies that she has arrived there, as can be seen from the oddity of 'She went to the shops but she hasn't got there yet. The explication below applies to the case where a to-phrase and a from-phrase are both present. Notice that this explication incorporates components which constitute the explication for $X$ moved from $A$ to $B$; see explication (1) above. This is consistent with the fact that $X$ went from $A$ to $B$ entails $X$ moved from $A$ to $B$.

6. $\mathrm{X}$ went from A to B (yesterday) =

before this $\mathrm{X}$ was in place-A

$\mathrm{X}$ wanted to be somewhere else

because of this, $\mathrm{X}$ moved for some time (yesterday)

because of this, after this $\mathrm{X}$ wasn't in place-A any more

$\mathrm{X}$ was in place-B

Before leaving English go, this might be a good time to observe that there are plenty of languages, even within Europe, which do not have exact semantic equivalents to this English word. For example, German has two everyday words for 'translational motion': gehen (roughly) 'go on foot' and fahren 'go, not on foot' (e.g. in a vehicle). To say in German the equivalent of She went to the shops, one has in fact to say a little more than this - because in choosing between gehen and fahren one must indicate whether she went under her own steam or not. A similar situation is found in Polish, which has iść 'move from one place to another on foot' and jechać 'move from one place to another in a vehicle' (verbs cited in infinitive form). In Polish, furthermore, these verbs can occur either in the 
imperfective form or with various perfective prefixes. For example, $X$ szedl (imperfective to the shops) means roughly ' $\mathrm{X}$ was walking', $X$ po-szedl means roughly ' $\mathrm{X}$ went', and $X$ $o d$-szedl z miejsca A 'X left (from) place A'. Po- and $o d$ - are perfective aspectual prefixes. In other words, different verbs will be used for 'was going along', 'went', and 'went from place-A': szedl, po-szedl, and od-szedl, if we are on foot; and jechat, po-jechat, and od-jecha1, if we are in a vehicle. Differences like these, which could be multiplied at length from other languages (cf. Wilkins and Hill 1995), are to be expected on the hypothesis that English go is a word of some semantic complexity.

\section{The meaning of English come}

How does come differ from go? One dimension of contrast is that come is 'goal-oriented'. As Miller and Johnson-Laird (1976: 531) put it: 'Someone who is coming will not have come until he has reached the destination (although someone who is going will have gone before he gets there)'. Notice also that in asking When did he come? we are asking about the time of arrival (though When did he go? asks about the time of departure). Come also implies or takes for granted that the goal of the motion is a known place. Thus, it sounds strange in normal circumstances to ask ? Where did he come to? though there is nothing odd about Where did he come from?

Most discussions, however, concentrate on another - more intriguing - property of come, namely, the way in which it imparts a particular perspective or point of view upon the motion event being reported. The most obvious situation in which come sounds more appropriate than go is when the speaker is at the destination at arrival time (also called in the literature 'reference time'). For example, if I work at a shop in town and I learn that John is intending to visit this shop tomorrow, it would sound quite odd if I reported this fact to you by saying ?John's going to the shop tomorrow. To put it this way would be, in effect, to ignore the fact that I will there when he arrives. It would be more natural to say, in this situation, John's coming to the shop tomorrow. (For the same reason, Come here! sounds fine, but 'Go here! sounds peculiar.) Come is also preferred to go if the speaker is at the destination at the time of speaking. For example, if I am at the shop talking with you over the telephone I can say John's coming to the shop tomorrow, even if we both know that I will not be there tomorrow. Examples like this can be brought under the heading of 'motion towards the speaker' (or more precisely, 'towards the speaker's location') providing this is understood as referring either to the speaker's current location or to his or her location at arrival time.

As mentioned earlier, it is often assumed from examples like these that the basic meaning of come is 'motion towards the speaker'. But English come is also possible, and sometimes even preferred over go, in a wide range of other contexts. This fact is usually put down to 'deictic projection', referring to a speaker's ability to imaginatively 'project' to some remote location. Before we examine this notion more carefully, let us review some of the different 'deictic conditions' under which come can be used. The exposition roughly follows Fillmore's $(1966,1971,1975 a)$ classic series of articles on the subject.

Come can be used in relation to the addressee's location. Suppose that you work at the shop (and that I do not). I could tell you that John's coming to the shop tomorrow on the assumption that you will be there when he arrives, or, regardless of the situation at 
arrival time, if you are there at the time of speaking. If I were to use the word go in such contexts, it would sound as if I don't know where you are (or don't care about your point of view).

Regardless of the speaker's and the addressee's locations, come is often preferred over go if what Fillmore calls the 'home base factor' is at work, that is, if the destination is one's literal home or another place one identifies with, such as a workplace or homeland. For example, if you and I both work at the shop, one of us could utter example (7a) below while we were at the pub after work. It might be thought that this example is accounted for by an inference that John is expecting one of us to be there, but consider example ( $7 b)$. One can easily imagine the Vice-Chancellor not being interested in lowly individuals such as you and me, but even so the sentence remains acceptable.

7a. It's a pity John's coming to the shop tomorrow, when neither of us will be there.

7b. It's a pity the Vice-Chancellor is coming to the Department tomorrow, when neither of us will be there.

The examples we have seen so far illustrate the fact that come is preferred over go if the so-called 'deictic centre' is the location of the speaker or of the addressee (at speech time or at arrival time), or the home base of the speaker or of the addressee. Come can also be found in discourse about 'third-persons', that is, where neither speaker nor addressee is a participant in the events being related. For instance, example (8a) below could occur in a public lecture about America as a nation, regardless of the speaker's own nationality and regardless of where the lecture takes place. Fillmore (1975) attributes this to the fact that America, in this context, is 'the subject of the narrative' and as such can function as a deictic centre. Example (8b) could occur in a discussion of a crime. Fillmore describes such examples as 'motion toward the central character' (or toward the central character's 'home base').

8a. People come to America with all manner of hopes and dreams.

8b. The thief came into her bedroom.

To complete this review of uses of come, it should be pointed out that there are certain contexts in which either come or go may be used equally felicitously - but with subtly different effects. For example, in (9a) and (9b) below the versions with come seem more sensitive to the expected location of the speaker or addressee. Both come and go may be embedded under a speech-act verb, such as tell in $(9 \mathrm{c})$, or under a verb of 'subjective-experience' such as wonder, as in (9d) (other similar verbs include think, hope, and wish). From the overall context, we understand that Lucy will be at her own party and at her graduation. Intuitively, the versions with come are somehow more sensitive to this fact about the location of the 'central character'.

9a. She came/went to the corner as we'd arranged, but I'd got stuck in the traffic and didn't make it.

9b. I came/went to the front door to let you in, but you had already left.

9c. Have you told Lucy that you're coming/going to her party?

9d. Lucy wonders if he'll come/go to her graduation. 
Finally, it should be mentioned that come can be used for 'accompaniment', as in Can I come with you? This should probably be analysed in terms of the phrasal expression come with, however (even when a with-phrase is not included, as in Do you want to come?, one is 'understood').

\section{Difficulties with the standard account ('deictic projection')}

Although come can be used in many situations aside from 'motion towards the speaker', it would seem curious to say that it has a different meaning in each of these situations (e.g. 'motion towards addressee', 'motion towards central character', 'motion towards speaker's home base', 'motion towards addressee's home base', 'motion towards central character's home base'). Intuitively, the meaning is the same in all these situations. As mentioned, one widely accepted explanation is that 'motion towards the speaker' is the basic (or prototypical) meaning and that the other uses are simply the result of an ability, which we all have, to adopt another person's point of view - to put ourselves into someone else's shoes.

As simple and appealing as it may seem, however, this explanation faces several difficulties. One of these difficulties, noted by Lyons (1977: 579) at the time he coined the term 'deictic projection', is the existence of unexplained restrictions on a speaker's power of 'projection' to remote spatio-temporal coordinates. Why should deictic projection be possible with come, for example, but impossible (or at least, highly restricted) with here and with now?

Perhaps more pressing is the fact, also noted by Lyons, that apparent equivalents of come in other languages, even European languages such as French (venir) and Italian (venire), do not allow deictic projection as freely as English come. Levinson (1983: 83) makes a similar observation about Japanese kuru - using kuru one cannot 'project' even to an addressee's location. For example, to say the equivalent of I'm coming (to you) in Japanese, one must say the equivalent (or near equivalent) of I'm going (to you). Differences in the deictic projection potential of putative equivalents of come and go have also been reported for Spanish and Turkish (Gathercole 1977, cited Wilkins and Hill 1995); and from personal knowledge I can add Malay and Yankunytjatjara to this list. If the flexibility of come is the result of an inherent human capacity for deictic projection, these facts seem rather strange: Why should the exercise of this capacity vary so much from language to language?

An alternative explanation is that the differences in the behaviour of 'come verbs' across languages are the result of differences in the lexical semantics of the verbs involved. Why, after all, should we assume that English come, French venir, Japanese kuru, Malay datang, and so on, are precise semantic equivalents? If come, venir, kuru, datang, and so on, have somewhat different lexical meanings, then their different ranges of use would make perfect sense (cf. Wilkins and Hill 1995). This line of reasoning brings us to the following idea. If one of the most distinctive properties of English come is its capacity to support 'deictic projection' $\beta-\beta$ that is, to suggest a point of view of someone other than the speaker him or herselfß-ßthen perhaps this property has its roots in the meaning of come itself; in other words, that the meaning of come is not simply 'motion towards the speaker', 
but something more complex.

\section{Explicating come}

Let us take another look at come. Is it possible to find an explication which would be consistent with its range of use, as reviewed above? Consider the following explication.

10. $\mathrm{X}$ came to place-A $=$

before this, $\mathrm{X}$ was somewhere

$\mathrm{X}$ wanted to be somewhere else

because of this, $\mathrm{X}$ moved for some time

because of this, after this $\mathrm{X}$ was in place-A

someone in this place could think:

$\mathrm{X}$ is in the same place as me

The first three components are the same as those proposed for go in explication (5). A slight difference from go, necessary to account for the 'goal orientation' of come, concerns the temporal perspective in component four. When we speak of X coming at some time, we view X's motion as the prior condition which has led to $\mathrm{X}$ being at the destination ('because of this, after this X was in place-A'). This temporal perspective differs from that involved with going, which views X's motion as the prior condition which has led to X's departure from a particular place ('because of this, after this X wasn't in this place any more').

However, these differences in temporal perspective are minor compared to the final component in the explication above, which is primarily responsible for the special quality of come. This component acknowledges the possibility of an 'egocentric' interpretation of $\mathrm{X}$ 's final location by an unidentified 'someone in this place': this unidentified person could interpret $X$ 's final location as ' $\mathrm{X}$ is in the same place as me'. In effect, this component installs a reference to a subjective point of view into the lexical meaning of come. Notice also that the subjective component appears without any specific time reference; it depicts a potential interpretation, not tied to any specific time.

It may seem odd that the potential interpretation ' $\mathrm{X}$ is in the same place as me' is attributed to an unidentified 'someone in this place'. But this is the only phrasing which is compatible with the fact that the implied person whose point of view is being taken into account may be the speaker, the addressee, or even a third person. According to the explication, the actual identity of the person is left open, to be inferred from the context. Let's run through some examples to see how it works, starting with John's coming to the shop tomorrow. As we have seen, this sentence is compatible with the situation of either speaker or addressee being at the shop. It is also compatible with the point of view of a third pers coming at on (for example, if Lucy works at the shop one may well say Does Lucy know John's coming to the shop tomorrow?) All these possiblilities are sanctioned by the explication. (A sentence like Come here!, strongly implies that identity of the implied person is the speaker him or herself, since the choice of the deictic word here implies that the speaker is in the particular place which is being indicated. However, even with Come here, it is possible to find contexts in which the imputed viewpoint belongs to 
someone other than the speaker; for example: Come here, your mother wants to speak with you.)

As Fillmore pointed out, a sentence like John's coming to the shop tomorrow is also possible if the person whose potential point of view is being recognised works at or owns the shop. In this connection it is important to take account of the fact that the meanings of many English place-nouns (like shop, house, room, school, office, and so on) refer to the possibility of someone being there. It is arguably this property, rather than the fact of a place being someone's 'home base' in a literal sense, which accounts for the acceptability of come in sentences of this kind.

Further, because the component 'someone in this place could think: $\mathrm{X}$ is in the same place as me' refers to a POTENTIAL interpretation, it is even compatible with hypothetical or imagined situations. This explains the effect of I came to the front door, but you had already left. In choosing the verb came (rather than went) the speaker alludes to his or her expectation that someone (evidently the addressee, in this case) would be able to think ' $\mathrm{X}$ is in the same place as me' $\beta-\beta$ even though in reality this expected situation never came to pass.

In sentences like People come to America with all manner of hopes and dreams the effect of come is to allude, rather vaguely, to a potential 'someone else in this place' recognising the immigrants as being 'in the same place as me', thus accounting for the faintly 'welcoming' quality of the sentence. This appears to be an improvement on Fillmore's claim that such sentences are possible because the place (America, in this case) is the 'subject of the narrative'. (Fillmore's explanation would predict that come could be used with equal ease about remote, unpopulated places, which appears not to be the case.)

\section{Concluding remarks}

If the analyses proposed in this paper are correct, the meanings of go and come are considerably more complex than often assumed. Even go, the simpler of the two terms, cannot be regarded as designating a primitive, universal (or near-primitive, near-universal) meaning. Incidentally, recognising the increased complexity of the meanings may help explain the finding from the child-language literature that full command over come and go is not gained till relatively late, cf. Tanz (1980).

On the proposed account, it is no longer necessary to invoke 'deictic projection' to account for the wide range of use of English come - at least, not if we reserve the term 'deictic projection' for a genuinely contains semantic pragmatic phenomenon. Instead, it has been argued, the meaning of English come contains SEMANTIC components which enable the word to be used in reference to the viewpoint of someone other than the speaker.

This kind of analysis enables us to see a way through an apparent paradox concerning words such as French venir, Japanese kuru, and Malay datang. These words are often assumed to be semantic equivalents of come, but yet it is also recognised that they are not as conducive to 'deictic projection' as is come. This puzzle can be resolved on the assumption that come, venir, kuru, and datang are not PRECISE semantic equivalents, but differ somewhat in their lexical meanings. Like Wilkins and Hill (1995), I believe it is time to drop the assumption that come and go are simple, universal (or near-universal) meanings, and to seek careful language-specific analyses of the deictic motion verbs of different 


\section{languages.}

\section{References}

Fillmore, Charles J. (1966) Deictic categories in the semantics of come. Foundations of Language 2:219-27.

Fillmore, Charles J. (1975) Santa Cruz lectures on deixis 1971. Bloomington: Indiana University Linguistics Club.

Fillmore, Charles (1983) How to know whether you're coming or going. In G. Rauh [Ed.], Essays on Deixis. Tubigen: Narr, pp. 219-227.

Gathercole, Virginia C. (1977) A study of the comings and goings of the speakers of four languages: Spanish, Japanese, English, and Turkish. Kansas Working Papers in Linguistics, vol 2: 61-94.

Goddard, Cliff (1991) Testing the translatability of semantic primitives into an Australian Aboriginal language. Anthropological Linguistics 33.1: 31-56.

Goddard, Cliff and Anna Wierzbicka (Eds.) (1994) Semantic and Lexical Universals: Theory and empirical findings. Amsterdam/Philadelphia: John Benjamins.

Goddard, Cliff (Ed.) (1997) Studies in the Syntax of Universal Semantic Primitives. Special Issue of Language Sciences 19(3).

Goddard, Cliff (In press, 1998) Semantic Analysis: A Practical Introduction. Oxford: Oxford University Press.

Goddard, Cliff and Anna Wierzbicka (Eds.) (Forthcoming) The Universal Syntax of Semantic Primes. Oxford: Oxford University Press.

Jackendoff, Ray (1983) Semantics and Cognition. Cambridge, MA: MIT Press.

Jackendoff, Ray (1990) Semantic Structures. Cambridge, MA: MIT Press.

Jackendoff, Ray (1996) Conceptual semantics and cognitive linguistics. Cognitive Linguistics 7.1: 93-129.

Leibniz, Gottfried Wilhelm (1981) [1765] New Essays Concerning Human Understanding. Translated by Peter Remnant and Jonathon Bennet. Cambridge: Cambridge University Press.

Levinson, Stephen C. (1983) Pragmatics. Cambridge: Cambridge University Press.

Locke, John (1976) [1690] An Essay Concerning Human Understanding. Abridged and edited with an introduction by John W. Yolton. London: Everyman's Library.

Lyons, John (1977) Semantics. Cambridge: Cambridge University Press.

Miller, George A. and Philip N. Johnson-Laird (1976) Language and Perception. Cambridge: Cambridge University Press.

Russell, Bertrand (1917) Mysticism and logic and other essays. 2nd Edition. London: George Allen \& Unwin Ltd. 
Sorabji, Richard (1988) Matter, Space and Motion. Ithaca, NY: Cornell University Press.

Stanwood, Ryo E. (1993) The hitchhiker's guide to Shake, wave, swing, and WAg. Working Papers in Linguistics, University of Hawai'i 22.2: 141-147.

Talmy, Leonard (1985) Lexicalization patterns: Semantic structure in lexical forms. In T. Shopen [Ed.], Language typology and syntactic description Vol III : Grammatical categories and the lexicon. Cambridge: Cambridge University Press: 57-149.

Tanz, Christine (1980) Studies in the Acquisition of Deictic Terms. Cambridge: Cambridge University Press.

Wierzbicka, Anna (1972) Semantic Primitives. Translated by Anna Wierzbicka and John Besemeres. Frankfurt: Athenäum.

Wierzbicka, Anna (1980) Lingua Mentalis: The Semantics of Natural Language. Sydney: Academic Press.

Wierzbicka, Anna (1988) The Semantics of Grammar. Amsterdam: John Benjamins.

Wierzbicka, Anna (1991) Cross-cultural Pragmatics: The semantics of human interaction. Berlin: Mouton de Gruyter.

Wierzbicka, Anna (1992) Semantics, Culture, and Cognition. Oxford: Oxford University Press.

Wierzbicka, Anna (1996) Semantics, Primes and Universals. Oxford: Oxford University Press.

Wilkins, David P. and Deborah Hill (1995) When "go" means "come": Questioning the basicness of basic motion verbs. Cognitive Linguistics 6.2/3: 209-259. 